\title{
2006-1309: A PROJECT EXPERIENCE IN POWER ENGINEERING DESIGN
}

ASPECTS

\section{Giri Venkataramanan, University of Wisconsin-Madison}

Giri Venkataramanan received the B.E. degree in electrical engineering from the Government College of Technology, Coimbatore, India, the M.S. degree from the California Institute of Technology, Pasadena, and the Ph.D. degree from the University of Wisconsin, Madison. After teaching electrical engineering at Montana State University, Bozeman, he returned to University of Wisconsin, Madison, as a faculty member in 1999, where he continues to direct research in various areas of electronic power conversion as an Associate Director of the Wisconsin Electric Machines and Power Electronics Consortium (WEMPEC). He holds six U.S. patents and has published a number of technical papers.

\section{Annette Muetze, University of Wisconsin-Madison}

Annette Muetze received the Dipl.-Ing. in Electrical Engineering of Darmstadt University of Technology /Germany and the degree in General Engineering of Ecole Centrale de Lyon /France in 1999. In 2004, she received the Dr. tech. degree in Electrical Engineering at Darmstadt University of Technology. Since May 2004, she has been working as Assistant Professor at the Electrical and Computer Engineering Department, University of Wisconsin-Madison, WI. She directs research in the areas of electric machine design and has recently been awarded the NSF-Career Award for leading research in the area of electric machine design optimization. 


\section{A Project Experience in Power Engineering Design Aspects}

\section{Introduction}

While electrical energy conversion systems and power supply systems form an integral component of modern electrical and electronic systems, student engineers graduating from modern electrical engineering curricula are rarely aware of real-world design concerns that stem from power and energy issues ${ }^{1}$. Furthermore, within the larger context of university education, a major concern is the disproportionately small share of minorities and women who opt to enter engineering careers ${ }^{2}$. In recent years, a large volume of scholarship on effective pedagogical techniques that aim at encouraging a positive learning climate for underrepresented groups has emerged $^{3}$. Beyond improving attrition rates among under-represented groups, these techniques have also been found to be effective in increasing the learning effectiveness of other groups of students ${ }^{4}$. As a concomitant development, the cognitive model for acquisition of knowledge held by educational psychologists has gradually evolved from a behaviorist towards a constructivist viewpoint ${ }^{5}$. Such a learning process built upon constructivist epistemic assumptions attributes a critical and enabling role to the situated variables in realizing cognition ${ }^{6}$. Learning is said to take place when it is situated in communities of practice, where the learners are extending their proximal zone of skills through their interactions with experts ${ }^{7}$. Arguably, such a viewpoint places an enormous burden in developing and implementing reforms within the existing institutions of education. If one takes a literal view of authentic experiences leading to education, even the role of a school becomes unclear ${ }^{8}$. It is therefore necessary to explore educational concepts that can be integrated with the setting of a university, while providing the necessary degrees of freedom to allow the constructivist development of learning opportunities. The purpose of this paper is to describe the engineering and pedagogic features of using an electric assisted bicycle as an authentic educational vehicle for introducing real world electronics engineering practice and only certain fundamental concepts of power engineering.

Section II gives an overview of effective pedagogical techniques that have been identified from the body of educational research, for incorporation into the power-engineering experience. In Section III, an outline of a related power-engineering summer experience that has been developed for undergraduate students is presented. This course has been developed around different instructional topics including analytical tools, technical skills, and laboratory experience. A brief concluding section summarizes the paper. The conclusions remark on the impact of the experience as it has been observed with the first generation course participants. Furthermore, other similar activities that have been developed as a result of this course are also discussed.

\section{Effective Pedagogy}

The Kolb's learning style inventory (KLSI) is based on the concept that the learning process follows a cycle of activities consisting of four distinct segments, namely (a) feeling (through concrete experience or $\mathrm{CE}$ ); (b) thinking (through abstract conceptualization or AC); (c) watching (through reflective observation or $\mathrm{RO}$ ); and (d) doing (through active experimentation

or $\mathrm{AE})^{9,10}$. It is readily evident that in the absence of a laboratory - real-world experience the learning cycle is plainly incomplete. 
The 'cone' of learning shown in Fig. 1 illustrates the effectiveness of various domains of experience from a pedagogic point of view ${ }^{11}$. The activities at the bottom of the cone are said to provide learning opportunities with higher motivational and retention levels compared to those that are at the top. The limited effectiveness of the 'top heavy' classical teaching styles with three weekly lectures supplemented with textbook reading may be readily observed from the figure. Course activities that are authentic, with an emphasis on real-world inspired and studentdirected laboratory projects provide the best learning opportunity possible within the context of a university setting.

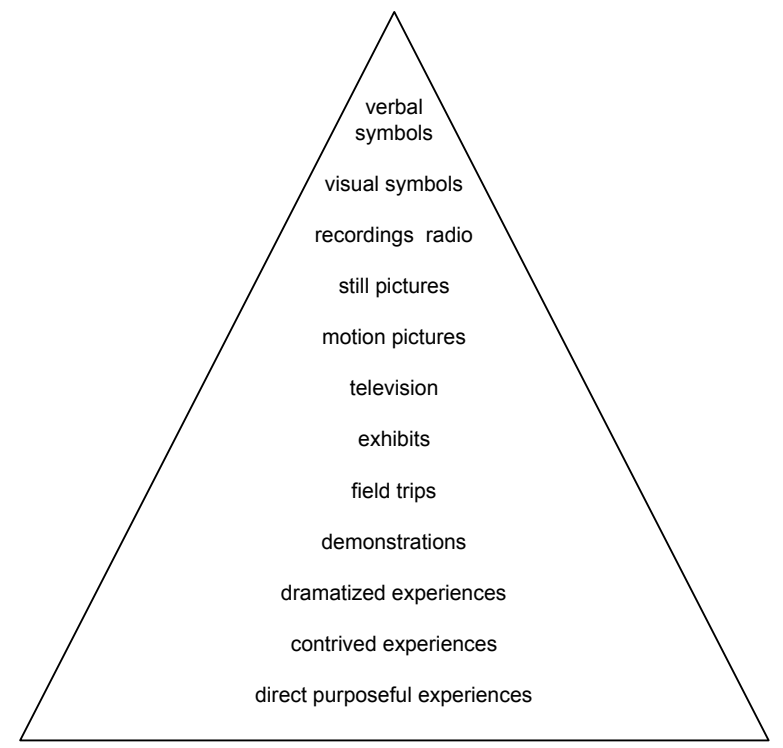

Fig. 1: The cone of experience, adapted from ${ }^{11}$.

Fig. 2 illustrates specifically how an inquiry-based learning process can be incorporated in a course. The real world is used as the bank from which topics of inquiry are chosen - this step addresses the $\mathrm{CE}$ segment of the learning process. Analytical tools that are necessary to address the questions are developed during lectures using an active participatory process, in a just-intime fashion - this step addresses the AC segment of the learning process. The students then receive a team assignment to complete within a strict deadline. Completion of the task-oriented assignment typically involves a nominal amount of research to be completed and the use of computational modeling tools - this segment addresses the RO segment of the learning cycle. Soon after the assignments are completed, the teams conduct laboratory experiments to verify their solutions and to examine the validity and limitations of the analytical model - this segment addresses the AE segment of the learning cycle. A discussion of the consequences and applications of the findings brings a tentative closure to the inquiry process. This step leads into the lesson theme for the next real world inspired inquiry process.

Thus, each inquiry-based lesson module is designed to proceed through the "problem identification $\rightarrow$ theoretical analysis $\rightarrow$ computer modeling $\rightarrow$ design solution $\rightarrow$ experimental study $\rightarrow$ problem solution and application' cycle, which is common in real-world engineering processes. The power engineering summer course described further extends through these cycles as described further. 


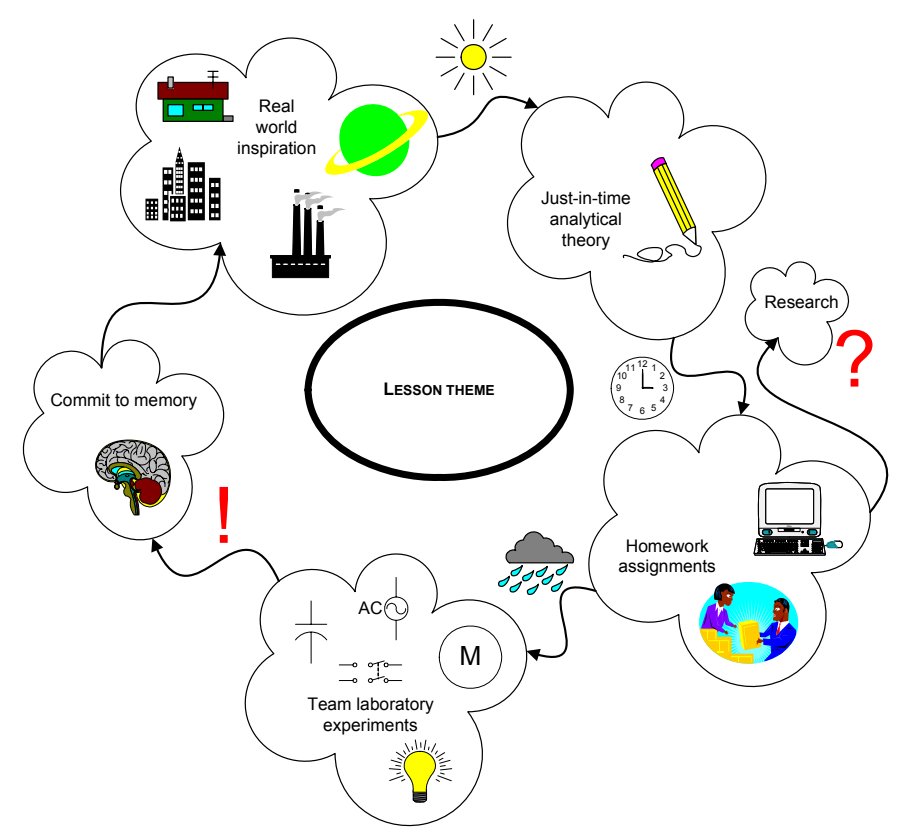

Fig. 2: An illustration of the inquiry based pedagogic process used in the course.

\section{E-Wheels - Power Electronics Summer Course}

The project E-Wheels was structured as a summer opportunity for college students in electrical and mechanical engineering programs. Completion of college physics including mechanics, electricity and magnetism may be considered to be prerequisites for the experience.

The bicycle, a readily accessible everyday object for people with a wide variety of age groups and backgrounds, is used as a learning vehicle to hone their mathematical, scientific and engineering skills in a hands-on fashion. Participating students study the design aspects and build an electric drive system for their own bicycles. Students develop and build a chopper circuit to control the speed of a hub-mounted dc motor fed from a lead-acid battery pack. The control circuit for the chopper consists of a simple current regulator with constant-off time built using a latching flip-flop and a comparator. The power circuit consists of a MOSFET and a diode along with a gate drive and a current sensor.

The project e-Wheels aims to enable students from less common backgrounds to become successful in an engineering educational program, while introducing them to the fundamental engineering concepts of electric machines, drive systems, and power electronics. To this aim, several cycles of inquiry-based lesson sequences have been carefully selected to fulfill several common instructional objectives. Each of these topics forms an inquiry-based learning cycle built around a project.

The program exposes the students to complete engineering process from conceptualization through prototyping, and raises their level of confidence in becoming successful engineers. Students feel a sense of ownership and personal learning achievement through the completion and demonstration of their project, unconnected to any grading process.

It should be made clear that the project is neither a design course nor a power-engineering course 
- in that students are provided with the complete design. It merely exposes students to the design and engineering aspects involved in a benchmark power engineering application that is of a personal and human scale. Therefore, the learning objectives reflect this, in not explicitly focusing on design or power engineering. Any acquisition of such aspects is incidental, over and above the 'street-skills' of navigating and actually implementing a pre-authenticated design, that is provided to the students.

A. Instructional objectives

1. To enlist various parts of a bicycle and make adjustments and tuning to ensure ride quality.

2. To understand the relationship between speed, force, angular velocity, torque, power and energy.

3. To understand the relationship between voltage, current, power, energy and charge.

4. To conduct experiments to determine speed, torque, and power in a human powered bicycle.

5. To identify motor specifications that meet certain speed and torque requirements.

6. To identify battery specifications that meet certain energy storage and voltage requirements.

7. To identify electric circuit components and their symbols.

8. To utilize a computer aided drafting program to draw circuit schematics.

9. To utilize a computer aided drafting program to draw printed circuit board layout.

10. To understand switching power control using choppers.

11. To assemble circuits on a breadboard.

12. To make electrical measurements using multimeter.

13. To use hand tools such as portable drill, screwdrivers, wrenches and punches.

14. To select, cut and strip wires to fit wiring needs.

15. To use a soldering iron, crimping and wire-ties to make circuit assemblies.

16. To apply fuses and switches to protect and control circuits.

17. To apply heat sinks to keep electric power components cool.

18. To use spreadsheet and mathematical software for making calculations and graphing data.

19. To develop skills in maintaining a laboratory notebook.

20. To use the World Wide Web for obtaining technical and engineering data of components.

\section{B. Project details}

Several variations of electrification strategies for bicycles are found in literature. However, simplicity was the main focus of the approach used in the project ${ }^{12-16}$. Figs. 3 and 4 show a block diagram and a circuit diagram of the motor drive system used for the electric bicycle. A front-wheel, hub-mounted drive system was chosen so that the existing rear-wheel manual drive train is unaffected and facilitates easy mechanical intervention into existing bicycles. A permanent magnet dc brush type motor was chosen to maintain simplicity of electronic control. The control consists of a simple throttle input from a handlebar-mounted potentiometer providing a current (proportional to the torque) command for the motor. Under-voltage and over-current protection circuits are added for safety. Prior to the assembly and control of the personal drive system, students study the prototype system by riding, examination and disassembly, as well as build and test a $15 \mathrm{~W}$ system using a kit of parts. This allows them to become familiar and comfortable with the actual system. Fig. 5 shows photographs of students working with the prototype bicycle and the project logo designed for student t-shirts. 


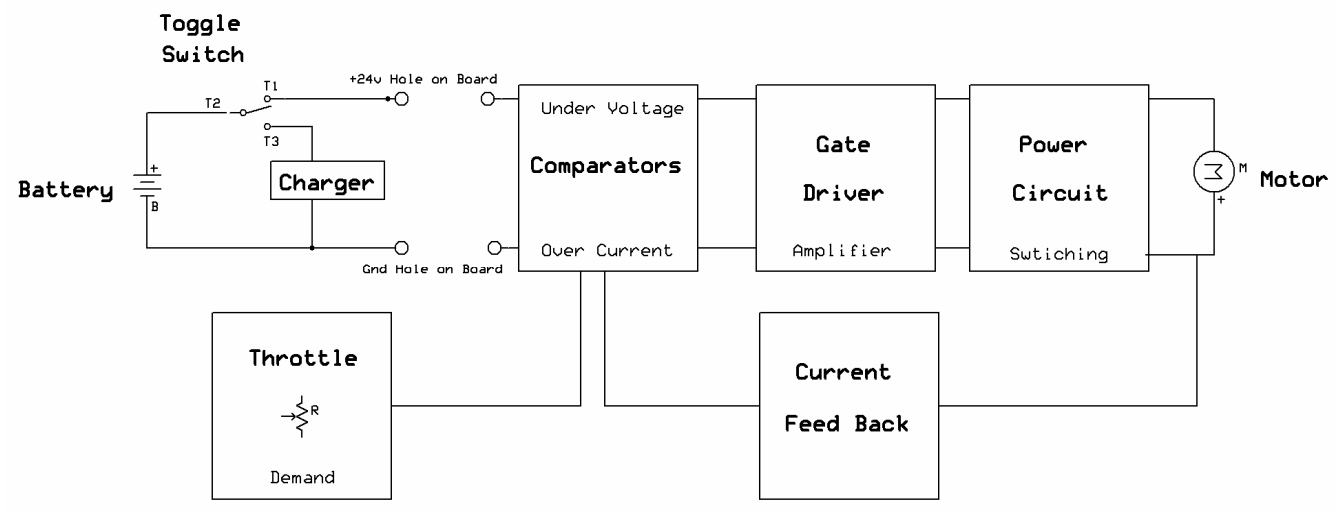

Fig. 3: Block diagram of bicycle motor drive system.

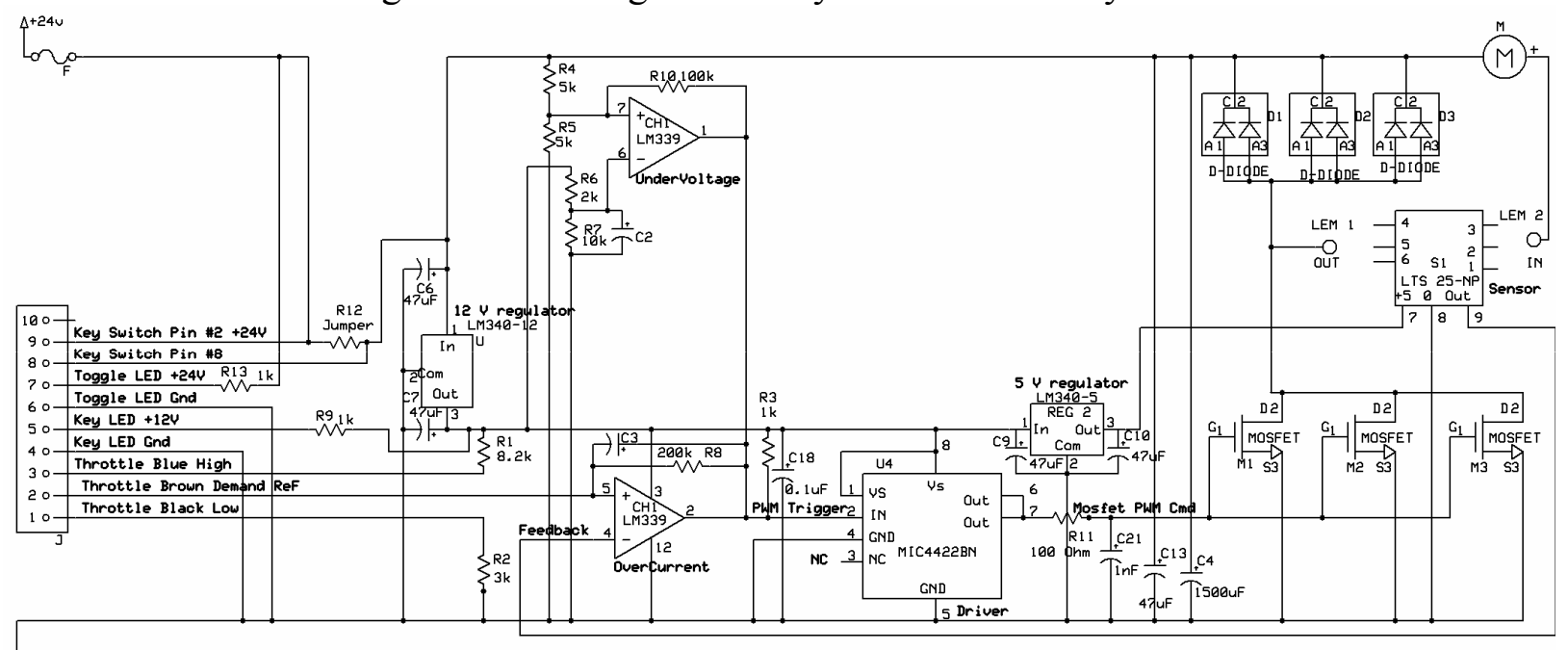

Fig. 4: Circuit schematic of bicycle motor drive system circuit board.
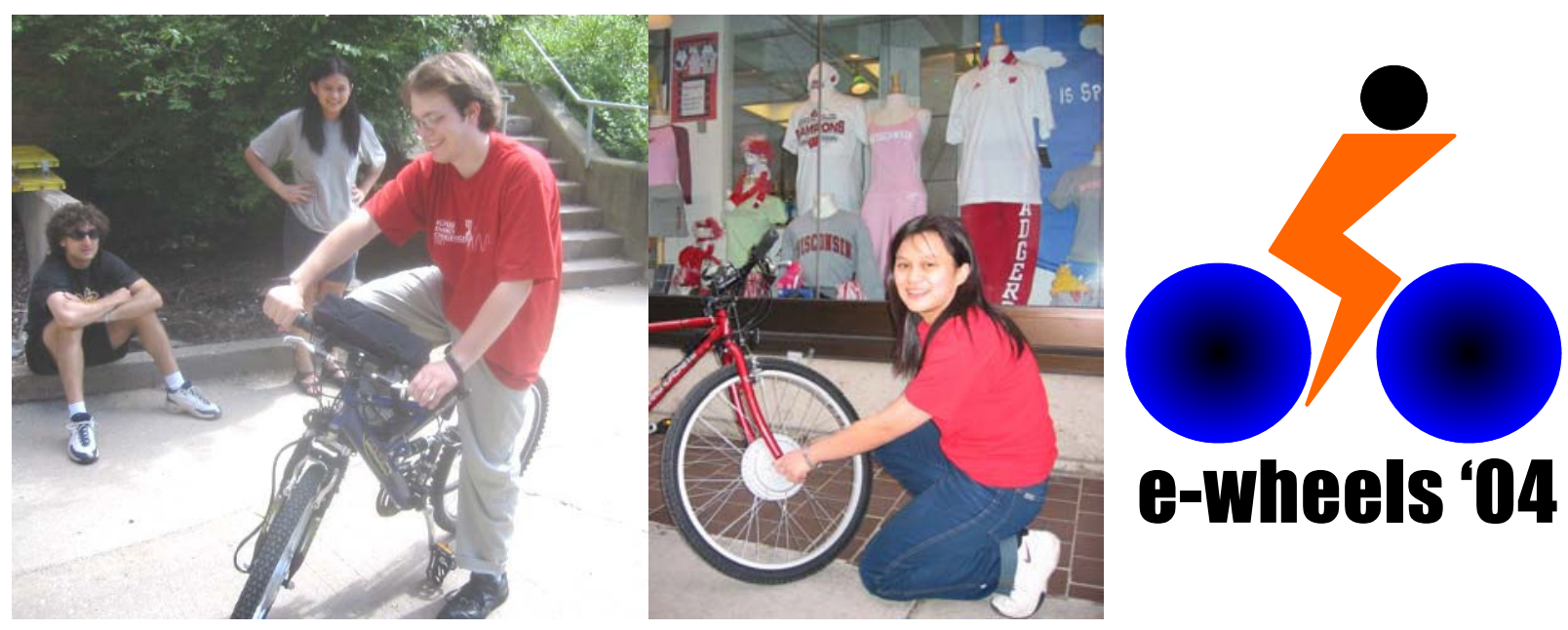

Fig. 5: Photographs of pilot students of the e-Wheels program with their bikes, and project logo. 
C. Course activities and timetable

\begin{tabular}{|c|c|l|l|}
\hline Week & Day & \multicolumn{1}{|c|}{ Activities } & \multicolumn{1}{|c|}{ Goal } \\
\hline \multirow{4}{*}{1} & 1 & Ride bike, measure voltage, current, speed & Introduce project and set pace \\
\cline { 2 - 4 } & 2 & Graph and interpret data, study prototype & Understand system block diagram \\
\cline { 2 - 4 } & 3 & Draw circuit schematic of prototype & Understand circuit schematics \\
\cline { 2 - 4 } & 4 & Disassemble and reassemble system & Understand physical connectivity \\
\cline { 2 - 5 } & 5 & Place order for system components & Understand engineering shopping \\
\hline 2 & 1 & Layout for printed circuit boards & Understand technical specifications \\
\cline { 2 - 4 } & 2 & Check printed circuit layout \& place order & Understand process reliability \\
\cline { 2 - 5 } & 3 & Test 15W motor drive components & Understand motor drive operation \\
\cline { 2 - 4 } & 4 & Assemble 15W motor drive & Learn soldering \\
\cline { 2 - 4 } & 5 & Test 15W motor drive system & Develop experimental process \\
\hline 3 & 1 & Check inventory of components & Understand conformance checking \\
\cline { 2 - 4 } & 2 & Assemble printed circuit board & Understand connection reliability \\
\cline { 2 - 5 } & 3 & Assemble external wiring & Understand interconnection process \\
\cline { 2 - 4 } & 4 & Test system operation & Apply experimental skills \\
\cline { 2 - 4 } & 5 & Ride bike home & Project completion \\
\hline
\end{tabular}

\section{Conclusions}

This paper documents the experiences gained during the development and implementation of a project-based college level introductory power electronics summer experience. The pedagogic objectives and project activities are presented in the paper. The cost of materials for each student project was about $\$ 400.00$, not including their own bicycles. The instructional infrastructure in terms of laboratory and shop facilities was found to be minimal, and commonly found at more engineering programs. In the preliminary offering of the course, there was one senior undergraduate student serving as a teaching assistant, with three enrolled students. The effectiveness of the program was found to be exceptional - one of the student participants (female) continued to study power engineering in graduate school, and the other student took up initial employment in an aerospace power engineering business. The authenticity of the experience is beyond question, in that students ride home aided by the creative output of their personal efforts. However, scaling the project beyond the pilot scale will require significant amount of staffing, space and material resources. A creative funding and staffing mechanism for the project will enable the benefits to be broadly realized. Furthermore, the bicycle may also be an ideal vehicle for introducing various other engineering fields such as structures, dynamics, materials, etc. on a hands-on basis in an effective and authentic manner. 


\section{Acknowledgements}

This work was supported in part by the ERC Program of the National Science Foundation under Award Number EEC-9731677. The authors would also like to thank Nikolay Kolev, Ying Chin Tan, Ray Marion, Patrick Flannery and Ted Bohn for their encouraging participation in this work.

\section{Bibliography}

[1] K.O.H. Pedersen, H Havemann, "An alternative approach to power engineering education," Proceedings of the IEEE Power Engineering Society Summer Meeting, 2000, Volume: 4, Page(s): 2085 -2090.

[2] W.A. Wulf, "Diversity in Engineering," The Bridge, Vol 28, No 4, Winter 1998.

[3] J.V. Gallos, "Gender and silence - implications of women's ways of knowing," College Teaching, Vol. 43, No. 3, pp. 101-105, 1995.

[4] E. Seymour, "The loss of women from science mathematics and engineering undergraduate majors: an explanatory account," Science Education, Vol. 79, No. 4, pp. 437-473, 1995.

[5] P.A. Cooper, "Paradigm shifts in designed education: From behaviorism to cognitivism to constructivism," Educational Technology, May 1993, pp. 12-18.

[6] B.G. Wilson and K.M. Myers, "Situated cognition and practical context," in D.H. Jonassen and S.M. Land (Eds.) Theoretical foundations of learning environments, Lawrence Erlbaum Associates, Mahwah, NJ, 2000, pp. 57-88.

[7] M. Cole, "The zone of proximal development: where culture and cognition create each other," in J. Wretsch (Ed.), Vygotsky and education, Cambridge University Press, Cambridge, England, pp. 1-45, 1990.

[8] J. Petraglia, "Reality by design: The Rhetoric and Technology of Authenticity in Education," Lawrence Erlbaum Associates, Mahwah, NJ, 1998.

[9] R.M. Felder and L.K. Silverman, "Learning styles and teaching styles in engineering education," Engineering Education, Vol. 78, No. 7, pp. 674-681, 1988.

[10] D.A. Kolb, Experiential Learning: Experience as the source of learning and development, Englewood Cliffs, N.J.: Prentice Hall, 1984.

[11] Edgar Dale, Audio-visual methods in teaching, revised edition, Holt, Rinehart and Winston, New York, 1961.

[12] B. Kumar and H. Oman, "Power control for battery-electric bicycles," in Proceedings of NAECON '93 National Aerospace and Electronics Conference, May 24-28 1993, 1993, pp. 428-434, vol 1.

[13] W.C. Morchin, "Trip modeling for electric-powered bicycles," in Proceedings of IEEE Technical Applications Conference, Northcon'96, Nov. 4-6 1996 1996, pp. 373-377.

[14] W.C. Morchin, “Battery-powered electric bicycles," in Proceedings of Northcon'94, Oct 11-13 1994, pp. 269274.

[15] H. Oman, "New technology for traveling with less energy," in Proceedings of the $32^{\text {nd }}$ Intersociety Energy Conversion Engineering Conference, Jul. 27- Aug. 1 1997, pp. 675- 680, vol 1.

[16] H. Oman, W.C. Morchin, and F.E. Jamerson, "Electric-bicycle propulsion power," in Proceedings of WESCON'95, Nov. 7-9 1995, 1995, pp. 555-560. 